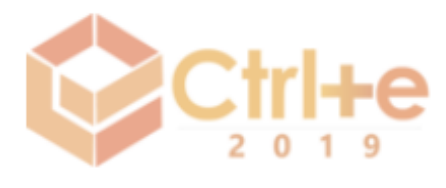

IV Congresso sobre Tecnologias na Educação (Ctrl+E 2019)

Recife, Pernambuco - Brasil

28 a 30 de agosto de 2019

\title{
Pensando Robótica em Versos e Prosa
}

\section{Giselle Maria Carvalho da Silva Lima, Maria do Carmo Lima, Marlene Coelho de Araujo}

\author{
Utec Gregório Bezerra - Prefeitura do Recife - R. Amaro Gomes Poroca, 1-109 - \\ Várzea, Recife - PE, 50741-530 \\ gisamcmary@gmail.com, maria.delima@prof.educ.rec.br, \\ milacoelhocegmail.com
}

\begin{abstract}
Resumo. Este artigo descreve o projeto Pensando Robótica em Versos e Prosa, proposto pelas professoras multiplicadoras e desenvolvido em escolas da RPA4 atendidas pelas mesmas, da Rede Municipal de Ensino do Recife. Tem como objetivo demonstrar como foi vivenciada a experiência exitosa do uso da robótica associada à leitura e produção textual, nas escolas municipais do Recife, bem como relatar a participação dos envolvidos neste processo de ensino aprendizagem. Foi vivenciado em aulas de $2 \mathrm{~h}$, com leitura de poemas e criação de protótipos de robótica para ilustrar os textos trabalhados, bem como confecção de vídeos utilizando os tablets e os cenários compostos por blocos de encaixe.
\end{abstract}

\begin{abstract}
This article describes the project Thinking Robotics in Verses and Prose, proposed by the multiplier teachers and developed in schools of RPA4 attended by them, of the Municipal Education Network of Recife. It aims to demonstrate how the successful experience of using robotics associated with reading and textual production in the Recife municipal schools was experienced, as well as to report the participation of those involved in this teaching-learning process. It was experienced in $2 \mathrm{~h}$ classes, reading poems and creating robotics prototypes to illustrate the texts worked, as well as making videos using tablets and scenarios composed of docking blocks.
\end{abstract}

\section{Introdução}

Estimular os estudantes ao prazer da leitura e da escrita são desafios vivenciados na prática docente e são temas essencialmente discutidos nos programas de formação continuada de professores, pois bem se sabe que a leitura e a escrita possibilitam ao estudante sonhar e criar dentro e fora da sala de aula. No cotidiano das salas de aulas, ler para responder perguntas é uma prática frequente, porém nem sempre desperta o interesse nos estudantes.

Assim, é necessário planejar outros propósitos de incentivo à leitura e escrita de modo que os estudantes enxerguem as duas práticas como algo prazeroso e estimulante. Nesta perspectiva, pode-se aliar a leitura e a escrita com as tecnologias inseridas no mundo atual e a escola precisa saber utilizá-las para favorecer o processo de ensino e aprendizagem. Diante dessa realidade, o projeto Pensando Robótica em Versos e Prosa 
pretende, através do uso das tecnologias, incentivar estudantes dos $5^{\circ}$ anos ao prazer da leitura e da escrita.

Este projeto foi pensado por professoras multiplicadoras para atuarem junto aos professores das turmas de $5^{\circ}$ ano, em três escolas municipais da Região PolíticoAdministrativa 04, da Rede Municipal de Ensino do Recife, no sentido de integrar o uso da tecnologia, destacando a robótica, ao desenvolvimento de atividades relacionadas ao componente curricular de Língua Portuguesa enfatizando o gênero textual Poema. Conforme o Programa Rede Aprendizagem, da Prefeitura do Recife, que busca garantir o acesso de estudantes e professores a

\begin{abstract}
“A Robótica por sua vez, constituem-se instrumentos contemporâneos que utilizam recursos que podem ser considerados sintonizados com a linguagem dos jovens que, sendo bem orientados pela mediação dos professores, podem se transformar em excelentes instrumentos de apoio ao processo pedagógico, ampliando a motivação e o interesse pelo conteúdo curricular. Com a devida orientação, esses equipamentos serão fortes aliados no estímulo à leitura e ao desenvolvimento de pesquisas em tecnologia e inovação, contribuindo inclusive no desenvolvimento de projetos de autoria e colaborativa para sistematização e publicação (ou socialização) das produções em plena sintonia com os fundamentos da Política de Ensino da Rede Municipal de Ensino do Recife" (RECIFE, 2017, p. 4).
\end{abstract}

O projeto teve como objetivo estimular nos estudantes dos Anos Iniciais do Ensino Fundamental o prazer da leitura e da escrita utilizando a robótica de encaixe como facilitadora da aprendizagem.

Já este artigo visa demonstrar como foi vivenciada a experiência exitosa do uso da robótica associada à leitura e produção textual, nas escolas municipais do Recife, bem como relatar a participação dos envolvidos neste processo de ensino aprendizagem.

\title{
2. Metodologia
}

Dentro da proposta de acompanhamento do professor multiplicador às escolas municipais da Rede Municipal de Ensino do Recife, foram pensadas, neste projeto, atividades que contemplassem o incentivo à leitura e a escrita e que fizesse articulação com as mais variadas tecnologias disponíveis na escola, sobretudo a robótica de encaixe, portanto foi escolhido o gênero textual Poema para o desenvolvimento do projeto visto o gosto dos estudantes pelo gênero em questão.

Então, foi pensado inicialmente um cronograma com 5 encontros, em turmas dos anos iniciais do Ensino Fundamental, especificamente os $5^{\circ}$ anos de algumas escola da Rede Municipal do Recife. Em cada encontro foi vivenciado a leitura de um poema de forma compartilhada seguido da reflexão do tema central do texto seguido da utilização da robótica de encaixe através da montagem do protótipo que representasse o poema disposto da seguinte forma:

\begin{tabular}{|c|c|}
\hline Poema & Montagem \\
\hline $\begin{array}{c}\text { Recife dos corações 1, do poeta Gleidson } \\
\text { Melo }\end{array}$ & Ponte \\
\hline
\end{tabular}




\begin{tabular}{|c|c|}
\hline A bailarina2, de Cecília Meireles & Bailarina \\
\hline O relógio3, de Vinícius de Moraes & Relógio \\
\hline Barco de papel4, de Manoel de Andrade & Barco a remo \\
\hline
\end{tabular}

Após a apresentação do projeto nas escolas aos coordenadores pedagógicos e professores regentes das turmas atendidas, foi elaborado um cronograma com os encontros, onde cada um teve a duração de $3 \mathrm{~h} / \mathrm{a}$ realizados na própria sala de aula dos estudantes.

No primeiro encontro foi vivenciado o poema Recife dos corações, do poeta Gleidson Melo, foi executada a montagem da Ponte, acompanhada no manual do professor (FORTES, 2010). Após a leitura e estudo do poema, os estudantes criaram os lados da ponte e posteriormente juntaram e compuseram as mesmas. Com as pontes montadas, os estudantes conversaram sobre a importância das pontes para a cidade do Recife, bem como enumeraram as mais conhecidas e importantes.

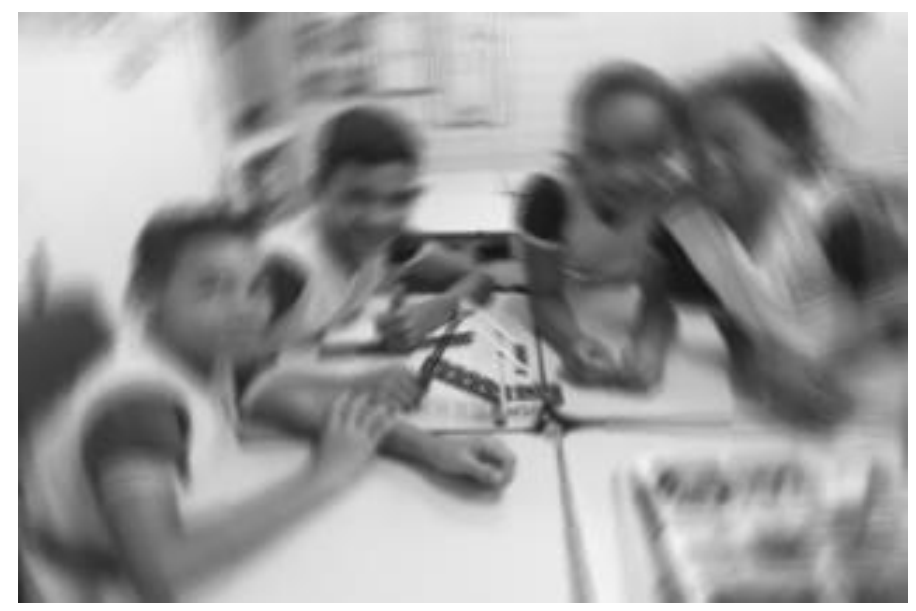

Figura 1. Montagem da Ponte. Acervo Pessoal

A bailarina, de Cecília Meireles, foi o poema escolhido para o segundo encontro onde foi trabalhado além do texto escrito, o vídeo e a música homônimos. Os estudantes puderam declamar e conversar sobre a poesia. A montagem executada posteriormente, seguindo o manual, também leva o mesmo nome bailarina. Depois de pronta, a bailarina realiza movimentos de giro, em sentido horário e anti-horário. Foi solicitado, ainda, que os estudantes desenvolvessem vídeos utilizando a câmera do tablet Positivo YPY AB10I e o aplicativo editor e criador de vídeo com imagens Photogrid. Para a

\footnotetext{
2 Disponível em https://www.tudoepoema.com.br/cecilia-meireles-a-bailarina/

3 Disponível em: https://www.letras.mus.br/vinicius-de-moraes/87218/

4Disponível em: https://palavrastodaspalavras.wordpress.com/2007/11/20/barco-de-papel-poema-demanoel-de-andrade/
} 
construção dos vídeos, os estudantes utilizaram os cenários confeccionados com os kits Lego 45100 Story Starter. Posteriormente, os estudantes fizeram a socialização das produções (montagem da bailarina e dos vídeos) em uma mostra na escola.

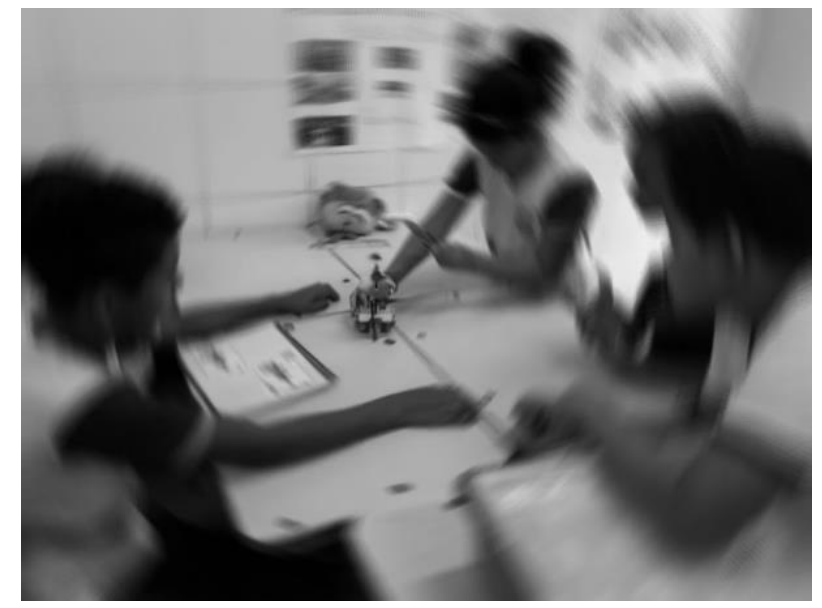

Figura 2 - Montagem da bailarina em movimento. Acervo pessoal.

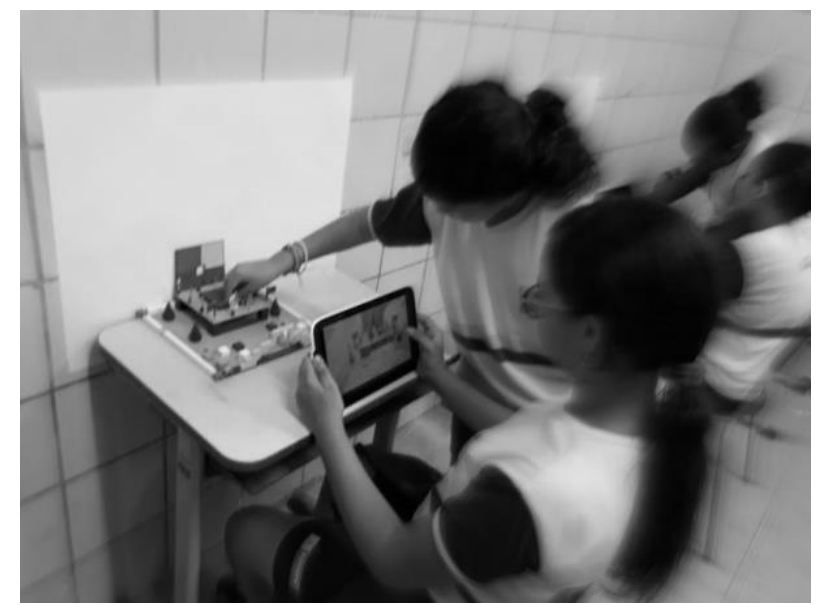

Figura 3 - Confecção de vídeos a partir das montagens sobre bailarina. Acervo pessoal. 


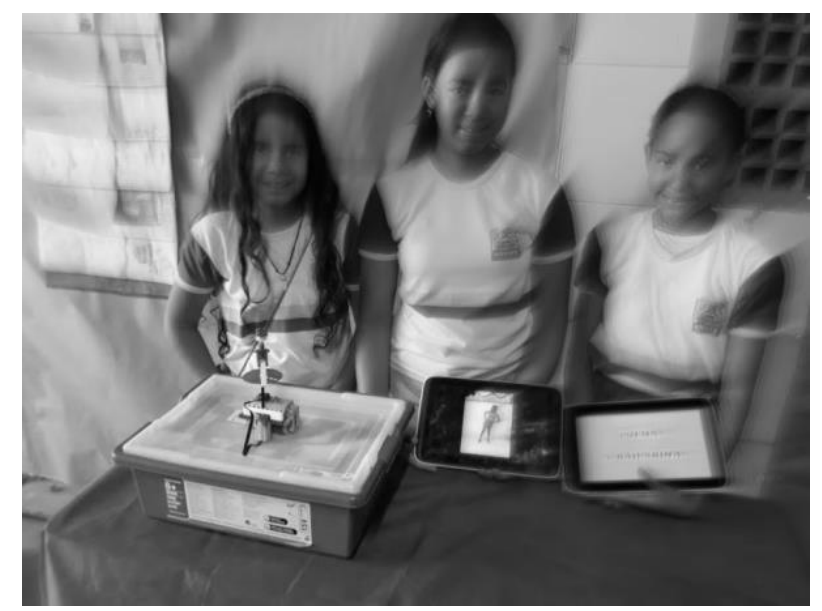

Figura 4 - Apresentação e socialização da montagem Bailarina e do vídeo confeccionado. Acervo pessoal.

Seguindo a sequência planejada no terceiro encontro foi vivenciado o poema $\mathrm{O}$ relógio, de Vinícius de Moraes, os estudantes se divertiram e declamaram fazendo a ritmo da poesia, quase cantando. $\mathrm{Na}$ ocasião, eles conversaram sobre os diversos tipos de relógio e de formas de marcar o tempo no curso da humanidade, seguidos pela montagem do protótipo do relógio.

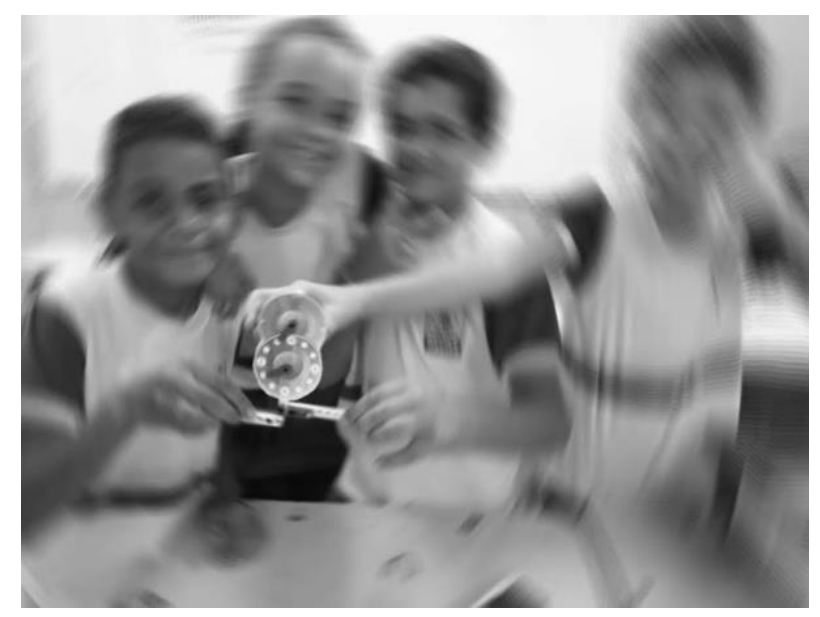

Figura 5 - Montagem 0 relógio. Acervo pessoal.

No quarto encontro foi trabalhado o poema Barco de papel, de Manoel de Andrade, além do texto em si, os estudantes confeccionaram um barquinho de papel de origami e conversaram sobre a infância, as brincadeiras e brinquedos. Na sequência, houve a montagem do barco a remo, seguindo o manual de montagem e os estudantes fizeram adaptações no protótipo para uma corrida entre os barquinhos. 


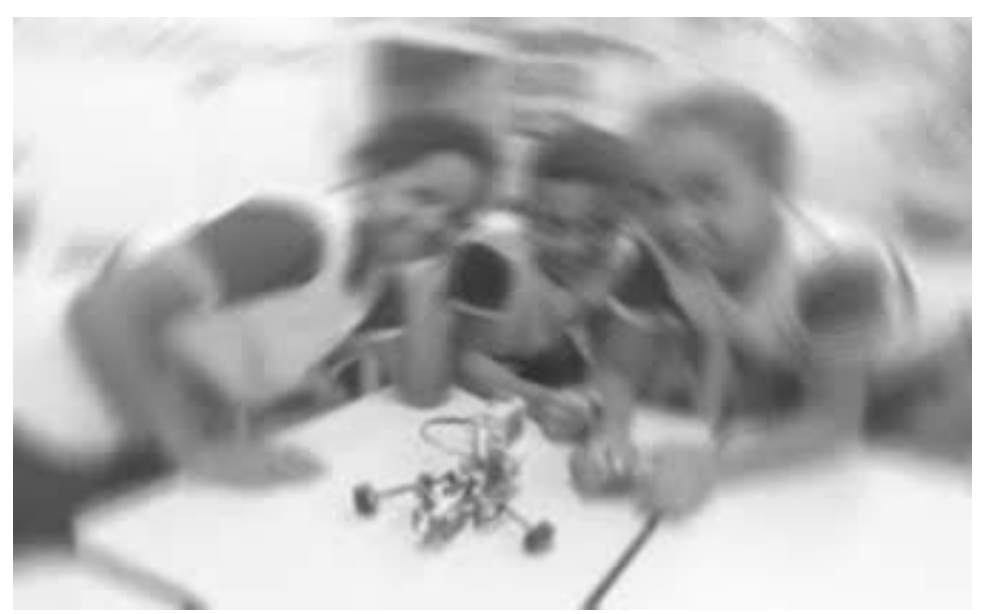

Figura 6. Montagem Barco a Remo. Acervo Pessoal.

Além da leitura dos poemas foi vivenciado a leitura o livro Bom dia todas as cores5, de Ruth Rocha, com posterior construção do camaleão. Nesta montagem, o camaleão, a partir do uso de um motor, alimentado com baterias de $1.5 \mathrm{~V}$, muda o lado da gravura do camaleão ora verde, num plano de fundo verde, ora laranja, num plano de fundo marrom.

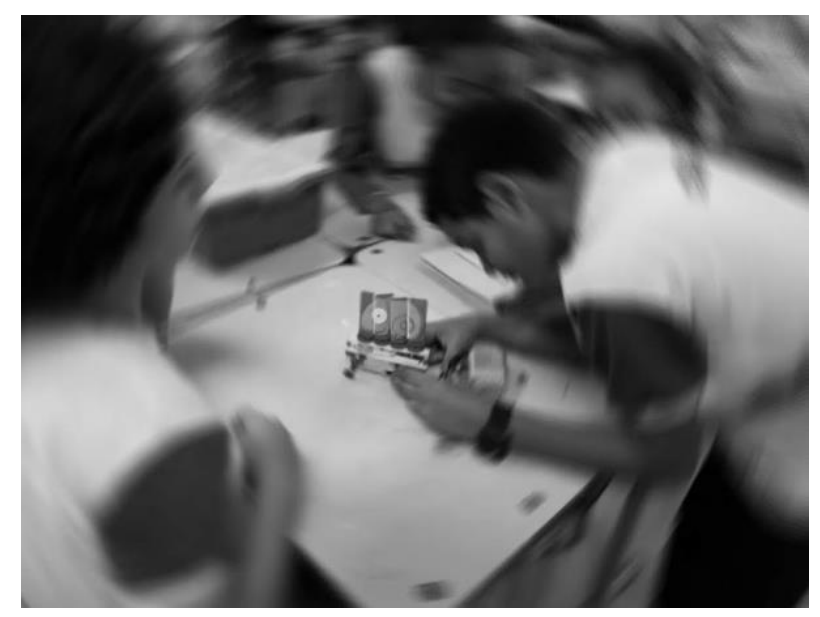

Figura 7 - Montagem Camaleão. Acervo pessoal.

O quinto encontro teve como proposta a criação de um texto em prosa pelos estudantes utilizando como base da produção as palavras-chaves: ponte, bailarina, relógio e barco, de acordo com as montagens feitas a cada encontro, como uma espécie de desafio utilizando a escrita. 


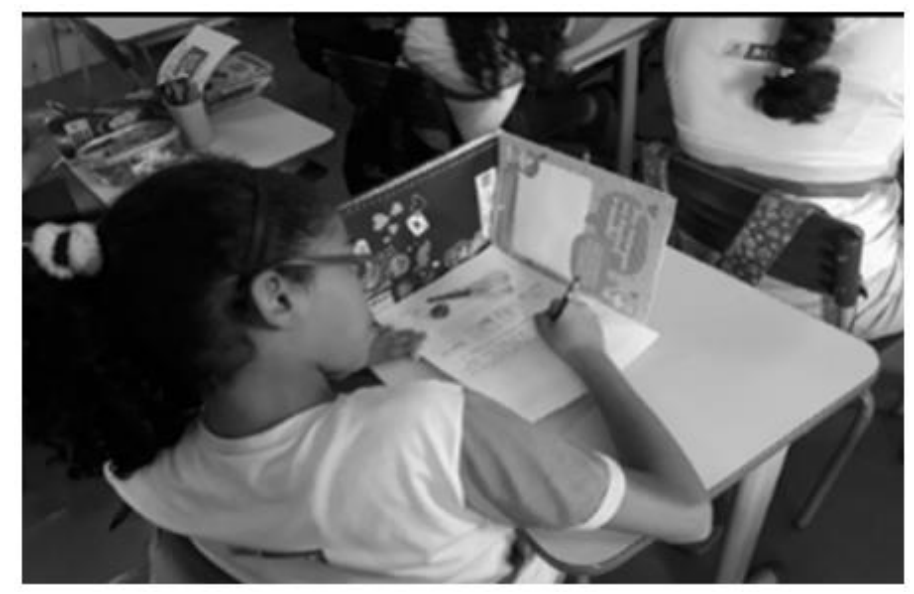

Figura 8 - Elaboração de texto - atividade final. Acervo pessoal.

Após as produções os estudantes puderam socializar seus protótipos e produções na Feira de Conhecimentos da escola, apresentando o que aprenderam.

\section{Conclusão e Perspectivas}

A vivência do projeto foi bastante positiva para o trabalho com o gênero Poema. Os estudantes se mostraram bastante participativos em todas as etapas e propostas do projeto. Os professores se mostraram satisfeitos com os resultados obtidos, tanto na contribuição com os conteúdos e eixos temáticos de Língua Portuguesa, quanto com a participação e desenvoltura dos estudantes nas montagens dos protótipos e confecção dos vídeos.

A cada encontro vivenciado os estudantes se envolviam com a atividade com interesse e empolgação. As relações interpessoais também foram trabalhadas a cada montagem feita, pois como o trabalho foi realizado em grupo, os estudantes passaram por situações de conflito onde tiveram a oportunidade de refletir sobre seus atos para com os outros. A etapa de socialização foi muito importante, tendo em vista o reconhecimento do esforço do aluno e a demonstração do seu aprendizado. A partir da vivência e resultados obtidos com este projeto, viu-se como é possível atrelar a robótica e suas noções aos conteúdos de Língua Portuguesa e a importância de desenvolver atividades deste tipo para favorecer a compreensão de outras disciplinas.

\section{Referências}

FORTES, Renata. "Fascículo de Educação para a Vida Zoom: introdutória: meu primeiro robô". $2^{\mathrm{a}}$ ed. Curitiba, PR: Zoom Editora Educacional, 2010

RECIFE. Secretaria de Educação. Política de ensino: tecnologias na educação. organização: Jacira Maria L'Amour Barreto de Barros, Élia de Fátima Lopes Maçaira, Katia Marcelina de Souza. Recife: Secretaria de Educação, 2015.

RECIFE. Secretaria de Educação. Diretoria Executiva de Tecnologia na Educação. Programa Rede de Aprendizagens. Prefeitura do Recife; Recife, 2017. Disponível em:http://www.portaldaeducacao.recife.pe.gov.br/sites/default/files/arquivos_inform ativos_home/programa_rede_de_aprendizagens.pdf. 